\title{
The Future of Video Playback Capability in College and University Classrooms
}

\section{Scott Spicer and Andrew Horbal ${ }^{\star}$}

\begin{abstract}
Instructional support is one of the primary reasons academic libraries collect video materials. Nonetheless, no one has published research into the perceptions of the people who install and maintain the equipment used to play these materials in college and university classrooms regarding the longevity of physical media formats. To address this gap in the literature, the authors of this paper surveyed classroom audiovisual (AV) support professionals from $49 \mathrm{ARL}$ institutions and conducted seven follow-up interviews. The results indicate steps that academic libraries need to take now if they want their video collections to remain relevant and accessible.
\end{abstract}

\section{Introduction}

The history of academic media libraries can be traced back to 1910, a mere fifteen years after the first public film screening, when the firm of Kline, Selig, and Spoor issued a catalog of films suitable for use by colleges and universities. ${ }^{1}$ For much of this time, collecting media was generally seen as the purview of media centers, not libraries. However, beginning with the advent of video recording and playback technology in the 1970s, the relatively low cost of videocassettes prompted libraries to begin building video collections of their own, and by the early 2000 s the number of academic libraries collecting audiovisual (AV) materials to support the general curriculum approached 100 percent. $^{2}$ Today it is typical for AV services at a college or university to be divided between a media center, which often resides within the information technology (IT) organizational structure and is responsible for technology classroom design and support, including support for video playback devices, and the library, which collects the materials that instructors and students play on those devices in physical formats such as Blu-ray, DVD, VHS, and (increasingly) digital formats such as streaming video.

Dividing AV services in this way is extremely logical: libraries do not generally have the resources to provide IT support for classrooms located elsewhere on campus; but, as ACRL's “Guidelines for Media Resources in Academic Libraries" note, they are uniquely qualified to build planned collections and provide the best physical and

\footnotetext{
* Scott Spicer is Media Outreach and Learning Spaces Librarian in the Walter Library at the University of Minnesota Libraries; e-mail: spic0016@umn.edu. Andrew Horbal is Head of Learning Commons in the McKeldin Library at the University of Maryland; e-mail: ahorbal@umd.edu. (02017 Scott Spicer and Andrew Horbal, Attribution-NonCommercial (http://creativecommons.org/licenses/by-nc/4.0/) CC BY-NC.
} 
bibliographic access to them. ${ }^{3}$ It does, however, occasionally cause problems for librarians, specifically in regard to playback technology and video format obsolescence.

As described by Kerstetter and Post (2000), media managers have been preoccupied since the 1980s with figuring out how to maintain existing technologies, making judgment calls on new equipment, and making decisions on what technologies should be removed from their service inventories. ${ }^{4}$ This picture of a profession grappling with rapid change is echoed in the profiles of media centers published in College $\mathcal{E}$ University Media Center Review, the field's flagship journal, throughout the 2000s, most of which mention video format shifts and playback technology advances as major issues. ${ }^{5}$ Posts on Videolib, the primary professional listserv for video librarianship, demonstrate that the decisions made by media managers throughout this period have had a major impact on libraries: discussion of the installation (or lack thereof) of DVD players in classrooms as a driving force behind library collection development decisions goes back at least as far as $2000,{ }^{6}$ and discussion of the implications of VCRs being removed from classrooms goes back at least as far as $2010 .^{7}$ Nonetheless, few researchers have explored what the presence or absence of playback devices in college and university classrooms means for academic library video collections. This paper addresses that gap in the literature through a survey of and follow-up interviews with classroom AV support professionals representing 49 ARL institutions regarding their perceptions about the durability of physical video formats.

\section{Background}

Ranker (2001) identifies stability, reliability, and ease of use as the most important considerations for faculty users of multimedia classrooms, ${ }^{8}$ and Schmidt and Rieck (2000) provide a decision tree for media managers faced with "making change decisions" that begins with the advice that "[t]here is no need to make changes unless problems exist, and those problems must be more than just perceived," ${ }^{\prime 9}$ both of which seem to weigh against rushing into new playback technologies and video formats. In contrast, Otto $(2014)^{10}$ and Intelligent Television et al. (2009) ${ }^{11}$ found that faculty prefer video content in web-based formats, and Chao and Zhao (2013) found that college students prefer streaming video to physical formats as well, ${ }^{12}$ suggesting that the time is ripe for a change. No studies have been published, however, that document what video playback devices are actually being added to and removed from classrooms.

Brancolini (2002b) documents the last major video format shift from VHS to DVD from the perspective of a media librarian, ${ }^{13}$ and Widzinski (2010) provides a tour of all the different $\mathrm{AV}$ formats that have been collected by libraries, from nineteenth-century lantern slide collections to Blu-ray, including an overview of the special requirements of each and a timeline for the obsolescence of formats currently in use. ${ }^{14}$ Provine (2002) discusses the problems that format shifts cause for libraries, most notably the "yawning gap that frequently develops between hardware and content development," which can result in titles only being available in obsolete formats. ${ }^{15}$ Laskowski (2011) describes library video acquisitions as needing to be viewed as "temporary additions to the collection" due to playback equipment obsolescence and identifies campus classroom playback equipment support policies as a factor for academic libraries to consider when deciding whether or not to invest in new video formats. ${ }^{16}$ Albitz (2001) advocates using "pre-existing policies for an established media format, the videorecording," instead of media-specific policies for every new format as a way of coping with format change. ${ }^{17}$ Scholtz (2002) argues that media collection development policies are the best way for librarians to "learn from past format and service transitions and changes and to efficiently transfer that knowledge to a new, emerging format,"18 but Laskowski and Bergman (2004) found that the majority of academic libraries do not have such policies specifically for their AV collections. ${ }^{19}$ 
Brancolini (2002a), ${ }^{20}$ Handman (2002), ${ }^{21}$ Laskowski (2000), ${ }^{22}$ and Laskowski and Bergman $(2004)^{23}$ all identify instructional support as one of the primary reasons academic libraries collect video. Otto (2014) examined faculty use of moving images in teaching and learning and found that libraries ranked fourth as a source for such resources after personal collections, YouTube and similar sites, and personal or departmental purchases. ${ }^{24}$ She concludes that libraries must reexamine their relationship to YouTube and other online video sources and determine whether they will choose to compete with them or focus on developing new, complementary services. ${ }^{25}$

Laskowski (2000) found that media centers historically have tended to maintain collections in obsolete formats. ${ }^{26}$ Imre and Cox (2009) argue that libraries need to continue to maintain physical media collections in obsolete formats, even during times of limited budgets, to ensure that the content in these collections that has never been released in a digital format is not lost until such time as it can be digitized, and they provide recommendations for dealing with such collections. ${ }^{27}$ King (2014) discusses the copyright issues associated with streaming video and notes that "the stable, reliable inventory of films that university faculty and students require simply cannot be guaranteed by any for-profit service that seeks primarily to serve a consumer market." 28

\section{Methods}

\section{Participants}

Study participants were drawn from classroom AV support professionals at the 115 Association of Research Libraries (ARL) colleges and universities listed on the ARL "Member Libraries" website. ${ }^{29} \mathrm{~A}$ list of names, contact information, job titles, and department affiliation was constructed using information on publicly accessible staff directories and organizational charts, supplemented by referrals from librarian and IT colleagues. The individuals on this list were contacted in advance to confirm that they were able and willing to represent their institution in our study; those who were not were asked to refer us to a colleague who might be. A total of 63 individuals confirmed their role and expressed interest in study participation, and 3 declined to participate; we either could not identify or did not receive a response from the remaining contacts. ARL institutions were selected as an ideal demographic to begin exploring the impact of video playback equipment obsolescence on academic libraries because of the size of the populations they serve.

\section{Survey}

The survey included both multiple-choice and open-ended questions to capture data at different levels of depth. The questions were developed collaboratively by both researchers, with the final set of questions distributed using Qualtrics software.

Questions addressed the type of support currently provided for classroom AV playback equipment, phased retirement plans for this equipment, and communication with stakeholders such as instructors and video collection managers. A full list of question is attached as appendix A. Survey participants were informed that the purpose of the study was "to capture current practice and future perspectives on support for classroom playback equipment from the classroom technology professionals responsible for this support" and provided with the following two definitions:

1. "We define 'playback equipment' as dedicated standalone equipment used to display video on a physical format such as VCRs, DVD players, Blu-ray players, $16 \mathrm{~mm}$ projectors, Laserdisc players, etc."

2. "We define 'phased playback equipment retirement plan' as a plan to, at some point in time, stop supporting classroom playback equipment."

The survey was distributed via e-mail during April and May 2015 using Qualtrics. Survey invitations were sent both to the 63 individuals who had previously expressed an 
interest in participating in the study and to the contacts we identified at the institutions that we did not receive a response from. We received 49 valid responses (one participant failed to complete the survey and is not included in the results) from 49 unique institutions, which represents 43 percent of the 115 ARL institutions we contacted. The response rate for people who previously confirmed interest in participating in the study was 65 percent, and the response rate for unconfirmed participants was 21 percent.

The majority of respondents indicated they were in leadership roles, which included responsibility for making decisions related to support for classroom AV playback equipment. Additional roles described included equipment design, equipment installation and maintenance, and help desk management.

\section{Follow-Up Interviews}

All survey respondents were later invited to participate in brief follow-up interviews. Seven respondents accepted this invitation. Interview questions were designed to provide greater context to survey responses on two primary topics: specific practices and perceptions related to the phased retirement of playback equipment; and the role of campus stakeholders in decision making and communications. A full list of questions is attached as appendix B.

\section{Data Analysis}

Survey responses were exported to an Excel spreadsheet for deeper analysis. Most of the survey data described in this article has been reported as is; however, some coding was required to better understand the results. The open-ended responses to question 13 (" $\mathrm{i}] \mathrm{f}$ your department has already or intends to implement a phased playback equipment retirement plan, what guidance did/would your department provide to an instructor with a DVD or VHS tape they want(ed) to show in class?") were coded and combined with the multiplechoice responses to that same question. Responses to questions 5 and 7 were merged for ease of reporting, as were responses to questions 8 and 9. Finally, the open-ended responses to question 12 (" $[\mathrm{i}] \mathrm{f}$ your department has either planned or you anticipate at some point in the future implementing a phased playback equipment retirement plan, what are/would be the reasons why?") were coded and combined with the multiple-choice responses to that same question, which were subsequently recoded for clarity.

\section{Limitations}

Question 7 of our survey, "[i]f yes, please specify the timeframe for phased retirement of classroom playback equipment support," is ambiguously worded: although our results seem to indicate that respondents interpreted this question correctly, it's possible that some were confused about whether we were asking about the timeframe for phasing out classroom playback equipment (what we intended) or just support for this equipment. Additionally, it's possible that respondents with separate timeframes for different types of equipment were not able to answer this question accurately.

Question 13 of our survey, "[i]f your department has already or intends to implement a phased playback equipment retirement plan, what guidance did/would your department provide to an instructor with a DVD or VHS tape they want(ed) to show in class?" also could have been better worded as "[i]f your department has already implemented or intends to implement a [...] plan, what guidance did/would your department provide to an instructor with a DVD or VHS tape they want(ed) to show in class?" All 46 survey participants who said that they have or will develop a plan answered this question and none of the 18 who selected "[o]ther (please specify)" used the open-ended comment field to express confusion, which seems to indicate that no one was unsure how to respond, but nonetheless the possibility exists that some respondents weren't entirely clear about what we were asking. 


\section{Results}

\section{Classroom AV Playback Equipment Support}

More than 9 out of $10(92 \%)$ respondents indicated that they provide support for AV equipment to all or most of the classrooms on their campuses. The remaining 8 percent indicated that they provide support for AV equipment to some campus classrooms. No respondents indicated that they do not provide any classroom playback equipment support. The specific type and level of support provided varied, but the vast majority of respondents indicated that the classrooms they support contain some combination of VHS, DVD, and Blu-ray players.

\section{Phased Retirement Planning by Equipment Type and Timeline}

A total of 94 percent of respondents indicated that they have a phased equipment retirement plan or anticipate developing one. Of the three remaining respondents, one described a practice that could be interpreted as retirement planning (replacement of VHS/DVD players with Blu-ray at the time of classroom upgrade) in the open-ended comments field, and another suggested that retirement would be conducted "organically" according to market forces at the time of classroom upgrade, not as a result of intentional planning.

Of the 46 survey respondents who indicated that they have a plan or anticipate developing one, 72 percent will do so within the next year; 85 percent will do so within the next three years; and 98 percent will do so within the next five years (see figure 1). The remaining respondent suggested that development of a phased retirement plan would likely be more than five years in the future.

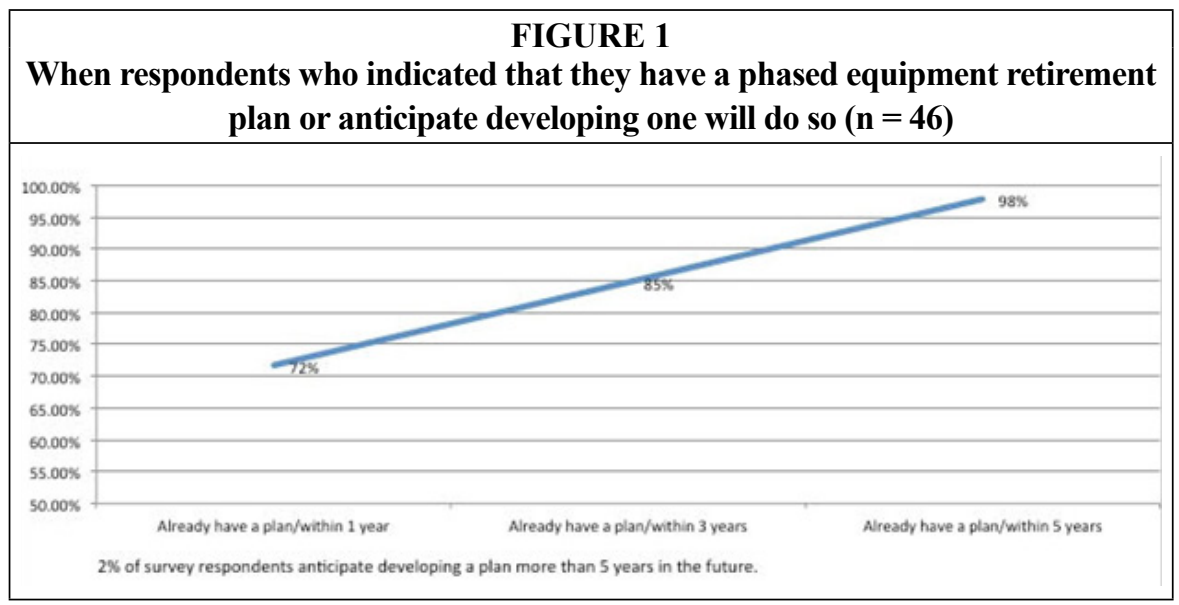

To provide information about the pace at which retirement proceeds once a plan has been developed, we asked respondents who indicated that they already had a phased equipment retirement plan to specify the timeline for it. Four out of $10(40 \%)$ reported that implementation was already under way, with the amount of time that it had been in progress ranging from one to seven years. Just half (50\%) reported that implementation was already under way or would begin within the next year, 63 percent said that it was under way or would begin within the next three years, and 77 percent indicated that it was under way or would begin within the next five years. One out of five $(20 \%)$ respondents reported that they did not have a definite timeframe, including two who specified that retirement takes the form of equipment breaking and not being replaced. The remaining respondent provided an unclassifiable response. 
A key theme that emerged from our survey was the decline of VHS playback support through a VCR as standard equipment in classrooms. Brancolini (2002a) found that the number of academic libraries collecting video approached 100 percent in the early 2000s..$^{30}$ Given that she cites instructional support as one of the main reasons academic libraries collect media ${ }^{31}$ and that DVD collections in academic libraries were not yet widespread, ${ }^{32}$ it is safe to assume that VHS players were a common sight in media-equipped college and university classrooms at this time. Therefore, the fact that on average, just 55 percent of our survey respondents reported that the classrooms they supported contained VCRs clearly indicates that VHS playback ability is ceasing to be a common feature in classrooms at respondents' institutions.

The seven brief follow-up interviews we conducted provided deeper insight into this decline. Six of seven interviewees suggested that they are actively withdrawing VCRs from their classrooms, while one respondent indicated that the library continues to support VHS/DVD combo units as standard equipment in classrooms. Though most participants said they are withdrawing VCRs when they cease to function, one participant suggested that they have removed all VCRs from their classrooms and for the most part are no longer providing support for them (upon request they may technically provide the service on a case-by-case basis, but they strongly encourage instructors to access this content through alternative means).

A majority of survey and interview respondents suggested that DVD playback capability will remain in classrooms for the foreseeable future: for example, none of the seven interview participants suggested that they are actively withdrawing DVD playback capacity (either through standalone DVD players or backwards-compatible Blu-ray players) from classrooms at this time.

\section{Reasons for Retirement Planning}

More than four out of five ( $83 \%$ ) respondents reported that marketplace considerations, specifically challenges in being able to purchase VHS and DVD playback equipment at a reasonable cost, were the number one factor in determining whether to phase out support for classroom AV playback equipment (see figure 2). Additional primary drivers cited included data suggesting that the use of playback equipment has been decreasing (65\%), a shift toward playback on instructor-owned devices (aka "Bring Your Own Device," or "BYOD") such as laptops or tablets (52\%), and instructor preferences for online digital delivery of video content (48\%). Less common responses included classroom playback equipment support not being a part of the department's long-term strategic planning (33\%), the existence of a campus digitization service $(30 \%)$, and budget reductions (11\%). Other factors cited by no more than one or two respondents through an open-text "other" option included the availability of playback equipment on request, the belief that playback equipment support was not a good use of funds, the fear that deteriorating playback equipment will damage videos, and concerns about faculty relying on physically deteriorating media.

The role of the marketplace as a primary factor for phasing out support for VHS figured prominently in the brief follow-up interviews we conducted as well: even the lone respondent still actively supporting VHS suggested that, since the VCR/DVD combo units they use are no longer readily available, they would likely not replace them as they break.

A number of respondents also explained that, while standalone DVD players may be removed from classrooms at their institutions, playback capability remains through either a dedicated classroom computer with a built-in DVD player and/or upgrading to Blu-ray players, which are backwards-compatible with DVD. 


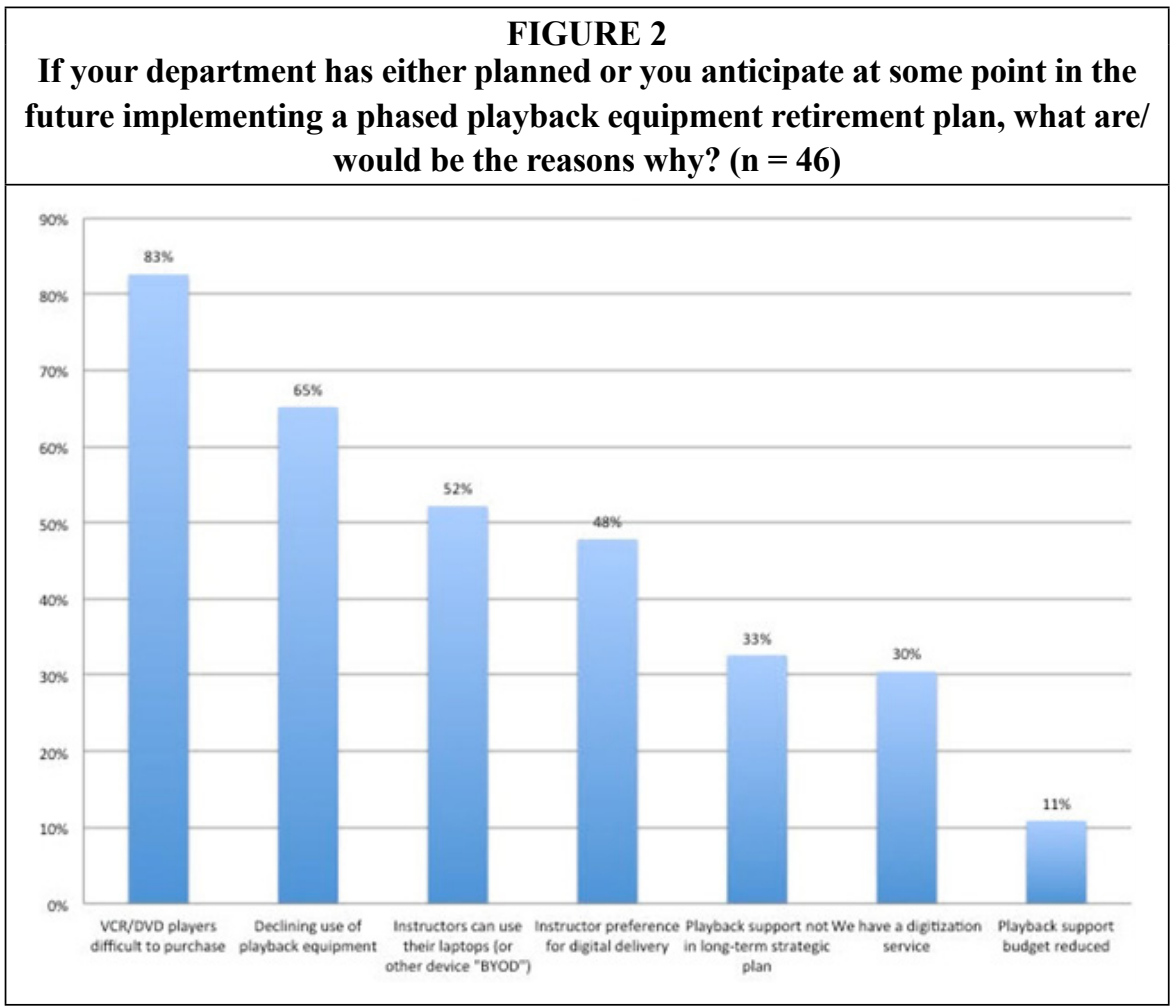

\section{Role of Campus Stakeholders}

Nearly nine out of ten $(89 \%)$ respondents who already have or think they might develop a phased retirement plan for classroom AV playback equipment indicated that they had coordinated or planned to coordinate with other departments on campus that support the use of video in the classroom. Open-ended responses suggested that this consultation process varies from institution to institution. For example, while many respondents suggested that they had consulted or planned to consult their library, several also mentioned communicating with colleges, departments, and individual instructors who held video collections. The nature of these collaborative relationships was generally described in positive terms, although one respondent noted in an openended comment that the library, their campus's provider of physical video collections, was not interested in working with them. VHS was the material type mentioned most frequently in open-ended comments, with digitization typically cited as the recommended option for sustained access.

\section{Guidance to Instructors}

Respondents with a phased retirement plan for playback equipment were asked what guidance their department provided/would provide to an instructor with a DVD or VHS tape he or she wanted to show in a classroom no longer outfitted with the appropriate type of playback equipment. By far, the most commonly suggested solution was for instructors to have materials digitized (93\%), with different types of physical (65\%) and online video solutions (61\%) lagging substantially behind (see figure 3). 


\section{FIGURE 3}

\section{Recommendations by Digital, Physical Media, or Online Solution $(n=46)$}

\begin{tabular}{|l|c|}
\hline Digitization solution & $93 \%$ \\
\hline $\begin{array}{l}\text { Physical media solution (BYOD, request equipment on demand from a } \\
\text { campus support service, use classroom PC for DVD playback, and so on) }\end{array}$ & $65 \%$ \\
\hline Online media solution (license streaming video content, YouTube, and so on) & $61 \%$ \\
\hline
\end{tabular}

Given the significant frequency of digitization as a recommendation, we further coded responses in this category by referral type (see figure 4). The majority of respondents referred instructors to the library or another campus video provider for digitization assistance $(74 \%)$, followed by recommendations to digitize materials themselves (53\%) or to employ a digitization service offered by the support department itself (33\%). Single responses included referral to an off-campus digitization vendor (Walgreens) and referral to an unspecified digitization service.

\begin{tabular}{|l|c|}
\hline \multicolumn{2}{|c|}{ FIGURE 4 } \\
\hline \multicolumn{2}{|c|}{ Recommendations by Digitization Referral Type (n = 43) } \\
\hline Referral to library or other campus video providers for digitization & $74 \%$ \\
\hline Recommendation to digitize the video themselves & $53 \%$ \\
\hline Referral to in-house digitization service & $33 \%$ \\
\hline Referral to off-campus digitization service & $2 \%$ \\
\hline Unspecified digitization referral & $2 \%$ \\
\hline
\end{tabular}

\section{Postimplementation Instructor Feedback}

More than half ( $57 \%$ ) of respondents with a phased equipment retirement plan reported receiving feedback from instructors. While several respondents reported that faculty initially expressed concerns, many suggested that negative feedback dissipated over time and was ultimately manageable. Much of this feedback appears to have been specifically related to VHS playback capability, which, as respondents noted, impacts a small segment of the overall instructor population. Survey respondents also suggested strategies for faculty communication that could be useful in raising campus awareness of equipment retirement plans, such as including faculty members on decision-making bodies and posting announcements on faculty listservs starting a full academic year before the beginning of phaseout.

\section{Discussion}

Analysis of the results of this study revealed three major areas in which academic libraries need to take action now to ensure the ongoing viability of their video collections: engaging in internal planning for format obsolescence, starting a dialogue with classroom AV support professionals at their institution around this issue, and investigating digitization options available to the campus community.

\section{Internal Planning for Format Obsolescence}

Although it is possible that VHS players will continue to be made available to instructors at some institutions by request or in specialized classrooms that support disciplines like film studies for which VHS will continue to have value as a format itself worthy of study, our data indicate that most respondents expect VCRs to be completely phased out from most classrooms at their institutions in the near future. 
Respondents were more sanguine about the long-term prospects for DVD playback capability: the only people who explicitly mentioned withdrawing DVD players from classrooms noted that they were replacing them with Blu-ray players, a device which is backwards-compatible with DVD, or computers equipped with DVD drives. Even here, though, our data revealed worrying signs. A total of 83 percent of survey respondents mentioned marketplace factors such as DVD and VHS players becoming difficult to find as a reason to develop phased retirement plans for playback equipment, and this was a major theme among participants in follow-up interviews as well. Other reasons cited by more than 48 percent of survey respondents include a decrease in the use of playback equipment, an increase in instructor preferences for online digital delivery of video content, and a shift toward playback on instructor-owned devices such as laptops or tablets. What all of these things have in common is that they are largely out of the respondents' control. Media librarians on the Videolib listserv have already reported problems acquiring content available only through subscription services like Netflix, ${ }^{33}$ whose terms of use permit only "personal" uses, ${ }^{34}$ and at least one prominent distributor of educational videos has mentioned the possibility of suspending the production of DVDs altogether and releasing content only in the form of streaming video. ${ }^{35}$ If these trends continue, marketplace factors and instructor preferences could conspire to rapidly accelerate DVD's and possibly even Blu-ray's progress toward obsolescence.

Unless academic libraries take action now, significant portions of their video collections will no longer be able to be used to support instruction, the most likely reason they acquired these collections in the first place. In the case of VHS, libraries should consider taking the following actions:

1. Replace VHS tapes with DVD, Blu-ray, and/or streaming video copies of the same titles. Many distributors offer discounts on DVDs that a library already owns on VHS, and many titles will be available on the secondary market in good condition, so this may not be unduly cost-prohibitive.

2. Format VHS collections to DVD or digital formats following the best practices outlined in the Video at Risk report ${ }^{36}$ of Besser et al. (2012), which clarifies the exemptions for copying audiovisual works available to libraries under $\S 108$ (c) of the United States Copyright Act, and/or ARL's (2012) Code of Best Practices in Fair Use for Academic and Research Libraries, ${ }^{37}$ which explains the options available under $\S 107$ of the United States Copyright Act. Principle \#3 of the latter document specifically references VHS. ${ }^{38}$ This approach would likely need to be supplemented by replacement purchases, but it still may not be overly expensive, especially for libraries with in-house digitization capabilities.

3. Work with the classroom AV support professionals on their campus to ensure that instructors can obtain VHS players on an on-demand basis (such as by "checking out" playback equipment the same way they check out the film that will be played on it) if such a service does not already exist.

In the case of DVD and Blu-ray, libraries should consider planning ahead and preemptively developing a strategy for dealing with items in these formats in anticipation of the inevitable day when they, too, will become obsolete. In addition to the three actions outlined above (which are equally relevant to other formats besides VHS), this might include proactively talking to educational video producers and vendors about their changing distribution models to avoid being caught off guard by any shifts.

\section{Starting a Dialogue with Classroom AV Support Professionals}

The good news for libraries is that our results indicate that classroom AV support professionals are eager to engage in dialogue around these issues. Nearly nine out of ten $(89 \%)$ respondents involved in or contemplating retirement planning for classroom $\mathrm{AV}$ 
playback equipment mentioned plans to consult campus providers of physical video collections to determine what impact this might have on them.

Libraries that are not already in regular contact with the classroom AV support professionals on their campus should strongly consider reaching out to them, keeping an open mind and respecting their expertise when doing so. Our data indicate that those libraries that do will find a partner eager to help them maximize the value of their video collections!

\section{Investigating Digitization Options}

In addition to helping them plan for the future of their video collections, our results revealed a second reason why libraries should proactively reach out to classroom AV support professionals on their campus. When asked what guidance these AV support professionals would offer an instructor with a DVD or VHS tape he or she wanted to show in a classroom that was not equipped with playback equipment for that format, 93 percent said they would tell the instructor to digitize the item, compared to only 65 percent who would suggest a physical video solution (such as obtaining a player from another source) and only 61 percent who would suggest an online video solution (such as licensing a streaming video version of the title). Of the 93 percent who recommend a digitization solution, 74 percent said they would refer the instructor to the library or another campus video provider for digitization, while 53 percent said they would advise the instructor to digitize the item themselves. Only 33 percent said that their department operated a digitization service.

These results are eye-opening for a number of reasons. First, the fact that only 61 percent of respondents said that they would recommend an online video solution such as licensing a streaming video version of the title or locating a legal copy online through YouTube or some other source may indicate that they are unfamiliar with the fact that these are common library services. Next, although 93 percent of classroom AV support professionals said that they would suggest digitization solutions, only $33 \%$ said that their department operated a digitization service. This indicates that most classroom AV support professionals think either that the library or some other video provider on their campus already offers a digitization service, that digitization falls outside of the scope of their responsibilities, or both. Finally, more than half of respondents (53\%) said that they would advise instructors to digitize items themselves. Although 26 percent of these respondents also indicated that their department operated a digitization service and 65 percent said they would also refer instructors to the library or another campus video provider for help with digitization, it seems clear from our data that a large number of instructors are at best being given the impression that self-digitization is a legitimate option. At worst, they are being explicitly encouraged to engage in this activity. This is potentially problematic because the types of materials available on DVD or VHS that instructors are likely to want to screen in class are typically protected by copyright. Thus, unless instructors are also being educated about when and under what circumstances digitization is and is not permissible (which was not mentioned by any respondents), it is possible that the activity they are explicitly or implicitly being encouraged to engage in will result in copyright violations.

Academic libraries and classroom AV support professionals need to work together to ensure that instructors at their institutions are not being given mixed messages about copyright. A good place to start is simply by investigating what digitization services are available on campus and in the surrounding community and making a joint decision about which one(s) instructors should be referred to. Another thing libraries can do is invest in staff education: as noted by ACRL's "Guidelines for Media Resources in Academic Libraries," "[a] comprehensive understanding of copyright law [...] is essential for 
providing library patrons with guidance in the use of media resources." The "Guidelines" also note that "[l]ibrary instruction programs should include the use of media resources for research, along with relevant copyright considerations for education." ${ }^{39}$ By creating materials related to copyright education and incorporating "[u]nderstanding of copyright laws pertaining to the proper use and citation of media resources" 40 into instruction efforts, libraries can give classroom AV support professionals a place to send instructors who want to know whether or not self-digitization is an appropriate option for them. Finally, outreach to classroom AV support professionals is a good way for libraries to advertise alternatives to digitization like streaming video licensing, reference assistance in locating legal copies of films online, and copyright-compliant digitization services offered through the library (such as electronic media reserves services) directly to instructors.

\begin{tabular}{|l|l|}
\hline \multicolumn{2}{|c|}{ KIGURE 5 } \\
\hline Key Finding & Recommendation \\
\hline $\begin{array}{l}\text { VHS playback ability will cease to } \\
\text { be a common feature in classrooms at } \\
\text { respondents' institutions in the near future. }\end{array}$ & $\begin{array}{l}\text { Academic libraries need to create plans to } \\
\text { reformat or replace their VHS holdings and/ } \\
\text { or begin circulating VCRs; otherwise their } \\
\text { VHS collections will be rendered useless for } \\
\text { instructional support. }\end{array}$ \\
\hline $\begin{array}{l}\text { Although DVD and Blu-ray are expected } \\
\text { to remain viable for the foreseeable } \\
\text { future, marketplace factors and instructor } \\
\text { preferences could conspire to rapidly } \\
\text { accelerate their progress toward } \\
\text { obsolescence. }\end{array}$ & $\begin{array}{l}\text { Academic libraries should monitor changing } \\
\text { distribution models for educational video } \\
\text { and preemptively develop a reformatting/ } \\
\text { replacement strategy for their DVD and } \\
\text { Blu-ray holdings. }\end{array}$ \\
\hline $\begin{array}{l}\text { Classroom AV support professionals are } \\
\text { eager to engage libraries in dialogue around } \\
\text { these issues. }\end{array}$ & $\begin{array}{l}\text { Academic libraries should reach out to the } \\
\text { classroom AV support professionals on their } \\
\text { campuses. }\end{array}$ \\
\hline $\begin{array}{l}\text { Instructors are being referred to the library } \\
\text { and other campus video providers for } \\
\text { digitization assistance and advised to } \\
\text { digitize videos themselves. }\end{array}$ & $\begin{array}{l}\text { Academic libraries and classroom AV } \\
\text { support professionals need to work together } \\
\text { to ensure that instructors are not being } \\
\text { encouraged to violate copyright law. }\end{array}$ \\
\hline
\end{tabular}

\section{Conclusion}

Because video formats evolve constantly and cannot be accessed without playback equipment, video collections present inherent challenges to libraries. This concern is especially acute in the academic library context, since responsibility for maintaining playback capability typically falls to support units located outside the library. As such, it is critical that library and classroom AV support professionals collaborate to develop solutions for sustained access to these collections.

Every day, instructors use video in their courses to illustrate complex core concepts that are better described in audiovisual mediums. Whether in the case of theater students learning from master performers in a Shakespeare course or nursing students learning valuable techniques to assist patients, ${ }^{41}$ instructional media is a thread woven into the tapestry of effective teaching and learning, spanning disciplinary contexts. Without sustained access to video materials, instructors and students are left with fewer tools from which to communicate these ideas. 
Beyond the classroom, video is ubiquitous in our culture. It is thus no surprise that academia is increasingly embracing multimedia as a research tool, evidenced (for example) in the digital humanities movement. ${ }^{42}$ Furthermore, many library video collections, which were developed over several decades, consist largely of specialized content not easily found elsewhere, creating an additional responsibility for libraries to consider the role their collections play in preserving culture.

For all of these reasons, it is clear that library video collections will continue to have an important role to play in academia. Looking forward, as more and more video materials are made available in digital formats, libraries will have an exciting opportunity to reconsider the role of their collections and related services. For instance, media librarians are well positioned to provide more customized support to assist users with their video needs regardless of location and format. This could include providing on-site digitization services, scanning course syllabi and using text-mining software to identify content needs, collaborating with subject librarians and instructional designers to provide instructors and researchers with targeted suggestions for video use, and creating new search tools for improved discovery of specialized content. Although some of these concepts have already been adopted, they are all worthy of greater exploration given the rapid changes in user practice and expectations. By doing so, libraries will better position themselves to meet user needs in a primarily digital media environment. 


\section{APPENDIX A. Survey Questions}

1. Consent form

2. Please describe your role in relation to classroom playback equipment support.

3. Does your department provide campuswide support or support to a specific college/academic unit?

a. All campus classrooms

b. Most campus classrooms (we provide most classroom playback equipment support, but there are some pockets of support services in colleges/departments)

c. Some campus classrooms (we support some classrooms, but most colleges/ departments have their own classroom playback equipment support services)

d. We do not provide any classroom playback equipment support through my department (either another central campus department provides this support or responsibility is distributed throughout colleges/departments)

4. Approximately what percentage of the classrooms that your department supports have the following?
a. VCRs
b. DVD players
c. Blu-ray players

5. Does your department/campus have a planned phased retirement of classroom playback equipment?
a. Yes
b. No

6. If yes, are there separate timelines for phased retirement of different types of playback equipment?

a. Just VCRs are being phased out

b. Phasing out of DVD players and VCRs are on separate timelines

c. Phasing out of all playback equipment is on the same timeline

d. Other (please specify)

7. If yes, please specify the timeline for phased retirement of classroom playback equipment support:

a. Generally already underway (please specify how long this has been in process)

b. Within the next year

c. Within the next 3 years

d. Within the next 5 years

e. Playback equipment has already been phased out

f. No definite timeframe, but we plan to phase out playback equipment at some point

g. Other (please specify)

8. If your department does not currently have a plan to phase out support for playback equipment, do you anticipate that it will eventually be necessary to develop one?
a. Yes
b. No 
9. If yes, when?
a. Within the next year
b. Within the next 3 years
c. Within the next 5 years
d. More than 5 years from now

10. If your department has already or will at some point implement a phased playback equipment retirement plan, did/will your department consult campus providers of physical video collections to determine what impact this might have on their services and instructor support?
a. Yes
b. No

\section{Comments}

12. If your department has either planned or you anticipate at some point in the future implementing a phased playback equipment retirement plan, what are/would be the reasons why? (select all that apply)

a. Our data suggest that usage of playback equipment has been going down

b. Budget for classroom playback equipment has been reduced

c. Budget for classroom playback equipment staffing/support has been reduced

d. VCRs are becoming difficult to purchase in the marketplace

e. DVD players are becoming difficult to purchase in the marketplace

f. Instructors are asking for materials to be delivered digitally

g. Future support for playback equipment is not in the long-term strategic goals of our department

h. Instructors can use their laptops to play DVDs, so classroom playback equipment is not necessary

i. We have a campus digitization service

j. $\quad$ Other (please specify)

13. If your department has already or intends to implement a phased playback equipment retirement plan, what guidance did/would your department provide to an instructor with a DVD or VHS tape he or she want(ed) to show in class? (select all that apply)
a. Bring your own playback device (DVD player, laptop, VCR, etc.)
b. Talk to the instructor's academic unit about requesting a playback equip- ment device
c. Digitize the video themselves
d. Suggest that your department can offer video digitization support
e. Refer the instructor to the library (or other campus video service) for digitiz- ing the video content
f. Refer to the library (or other campus video service) for licensing the video content
g. We did/would not provide any guidance
h. Other (please specify)

14. If your department has/had a phased playback equipment retirement plan, have/ did you coordinate with other departments on campus that support the use of video in the classroom (for example, the library, instructional designers/educational technologists, video digitizing support service, and the like) on the timeline and/or campus communications? 

a. Yes
b. No

\section{Comments}

16. If your department has announced a phased playback equipment retirement plan, did you receive any feedback from instructors?
a. Yes
b. No

\section{Comments (on Question 16)}

18. Comments (on Question 8- respondents who answered "no" to this question were skipped ahead to the end of the survey)

\section{APPENDIX B. Follow-Up Interview Script}

1. In our survey, a number of participants indicated that they only have plans to retire VCRs. Other participants indicated that they have plans to phase out both VCR and DVD players. Are you making plans to phase out DVD players in the classrooms you service?

Prompts if yes:

- What are you replacing DVD players with? (Blu-ray players, computers, or other formats)

- What physical media formats (if any) do you think will replace DVD and/or Blu-ray?

Prompts if no:

- Why not?

- Our survey results indicate that many of your colleagues are replacing DVD players with Blu-ray players. Have you considered this as well? If not, why not?

- What physical media formats (if any) do you think will replace DVD and/or Blu-ray?

2. Have you contemplated/are you preparing for a physical medialess future? How close are we to such a future?

3. Question \#10 of our survey ("[i]f your department has already or will at some point implement a phased playback equipment retirement plan, did/will your department consult campus providers of physical video collections to determine what impact this might have on their services and instructor support?") was not designed to be read as passing judgment, but in retrospect we believe could have been perceived that way by survey participants. Can you please explain how conversations with key campus stakeholders have gone at various points during the phased retirement decisionmaking, planning, and/or communication processes? 


\section{Notes}

1. William D. Schmidt and Donald A. Rieck, Managing Media Services: Theory and Practice (Englewood, Colo.: Libraries Unlimited, Inc., 2000), 5.

2. Kristine R. Brancolini, "Video Collections in Academic Libraries," in Video Collection Development in Multi-Type Libraries: A Handbook, ed. Gary P. Handman (Westport, Conn.: Greenwood Press, 2002a), 48.

3. ACRL Guidelines for Media Resources in Academic Libraries Task Force, "Guidelines for Media Resources in Academic Libraries." ACRL, available online at www.ala.org/acrl/standards/ mediaresources [accessed 7 September 2015].

4. John P. Kerstetter and Richard Post, "A History of Media Management in Higher Education," College \& University Media Review 7, no. 1 (2000): 15-20.

5. Deborah Bailey, "Integration, and Transformation: Media Services at the Dean B. Ellis Library, Arkansas State University," College \& University Media Review 7, no. 2 (2001): 73-86; Carl Brandon, "Media Services at Cedarville University," College \& University Media Review 11, no. 2 (2005): 37-47; Jeff Keezel, "The Media and Technology Center at Union Theological Seminary \& Presbyterian School of Christian Education," College \& University Media Review 8, no. 1 (2001): 57-63; Scott Menter, "Classroom Technology Services at UNLV," College \& University Media Review 17 (2011): 9-18; Allan C. Rough, "Nonprint Media Services Library at the University of Maryland," College \& University Media Review 12, no. 2 (2006): 47-60; Judy C. Routhe, "Media Services at Winona State University," College \& University Media Review 10, no. 2 (2004): 63-74; Elia Schomer, "Instructional Media Services at Lehigh University," College \& University Media Review 10, no.1 (2003): 37-50; Steve Wilson, "Media Services at St. Edward's University," College E University Media Review 12, no. 1 (2005): 31-36; Susan M. Zvacek, "Instructional Development and Support at the University of Kansas," College \& University Media Review 13 (2007): 9-14.

6. Kristine R. Brancolini to Videolib listserv, August 22, 2000, "Re: DVD Info," available online at www.lib.berkeley.edu/VideoLib/archive/0008/0173.html [accessed 8 September 2015].

7. Beth Traylor to Videolib listserv, April 1, 2010, "Campus Support for VHS," available online at www.mail-archive.com/videolib\%40lists.berkeley.edu/msg01029.html [accessed 8 September 2015].

8. Rich Ranker, "White Paper on Support Services for Multimedia Classrooms," Educause, last modified August 5, 2001, available online at https://net.educause.edu/ir/library/html/sac0103/ sac0103b.html [accessed 8 September 2015].

9. Schmidt and Rieck, Managing Media Services, 204-07.

10. Jane Johnson Otto, "University Faculty Describe Their Use of Moving Images in Teaching and Learning and Their Perceptions of the Library's Role in That Use," College \& Research Libraries 75, no. 2 (2014): 130-33.

11. Intelligent Television, Copyright Clearance Center and New York University, "Video Use in Higher Education: Options for the Future," available online at http://intelligenttelevision.com/ files/42-intcccnyuvideo_and_higher_edjune_2009_2.pdf [accessed 25 May 2017].

12. Chiang-nan Chao and Saibei Zhao, "Emergence of Movie Stream Challenges Traditional DVD Movie Rental: An Empirical Study with a User Focus," International Journal of Business Administration 4, no. 3 (2013): 26-28.

13. Kristine R. Brancolini, "DVD: Not If but When," in Video Collection Development in Multi-Type Libraries: A Handbook, ed. Gary P. Handman (Westport, Conn.: Greenwood Press, 2002b), 419-32.

14. Lori Widzinski, "Step Away From the Machine': A Look at Our Collective Past," Library Trends 58, no. 3 (2010): 358-77.

15. Rick E. Provine, "Video Collections into the Future," in Video Collection Development in Multi-Type Libraries: A Handbook, ed. Gary P. Handman (Westport, Conn.: Greenwood Press, 2002), 446.

16. Mary S. Laskowski, Guide to Video Acquisitions in Libraries: Issues and Best Practices (Chicago, Ill.: American Library Association, 2011), 2-3.

17. Rebecca S. Albitz, "Establishing Access Policies for Emerging Media in Academic Libraries," Collection Management 25, no. 3 (2001): 1-9.

18. James C. Scholtz, "Developing Video Collection Development Policies to Accommodate Existing and New Technologies," in Video Collection Development in Multi-Type Libraries: A Handbook, ed. Gary P. Handman (Westport, Conn.: Greenwood Press, 2002), 274.

19. Mary S. Laskowski and Barbara J. Bergman, "Academic Media Center Collection Development and Circulation Policies: A Comparative Analysis," College \& University Media Review 10, no. 2 (2004): 91.

20. Brancolini, "Video Collections in Academic Libraries," 48-49.

21. Gary P. Handman, "The Rights Stuff: Video Copyright and Collection Development," in 
Video Collection Development in Multi-Type Libraries: A Handbook, ed. Gary P. Handman (Westport, Conn.: Greenwood Press, 2002), 288-90.

22. Mary Schneider Laskowski, "The Academic Media Center: Where We've Been, Where We Are, and Where We Are Going," College \& University Media Review 7, no. 1 (2000): 25-27.

23. Laskowski and Bergman, "Academic Media Center Collection Development," 90.

24. Otto, "University Faculty Describe Their Use of Moving Images," 126.

25. Ibid., 140.

26. Laskowski, "The Academic Media Center," 24.

27. Andrea Imre and Elizabeth J. Cox, "Are We on the Right Track? Issues with LP Collections in U.S. Academic Libraries," Notes 65, no. 3 (2009): 475-86.

28. Rachel King, "House of Cards: The Academic Media Center in the Era of Streaming Video," The Serials Librarian: From the Printed Page to the Digital Age 67, no. 3 (2014): 293.

29. "Member Libraries," Association of Research Libraries, last modified January, 2013, available online at http://old.arl.org/arl/membership/members.shtml [accessed 2 May 2016].

30. Brancolini, "Video Collections in Academic Libraries," 48.

31. Ibid., 48-49.

32. Brancolini, "DVD: Not If but When," 426.

33. Allen Reichert to Videolib listserv, June 12, 2015, “Netflix Produced Documentaries," available online at www.mail-archive.com/videolib\%40lists.berkeley.edu/msg12580.html [accessed 2 May 2016].

34. "Netflix Terms of Use," Netflix, last modified September 15, 2014, available online at https:// help.netflix.com/legal/termsofuse?locale=en\&docType=termsofuse [accessed 31 March 2016].

35. Jonathan Miller to Videolib listserv, November 3, 2015, "No more DVDs?" available online at www.mail-archive.com/videolib\%40lists.berkeley.edu/msg13019.html [accessed 2 May 2016].

36. Howard Besser et al., "Video at Risk: Strategies for Preserving Commercial Video Collections in Libraries," last modified December 2012, available online at www.nyu.edu/tisch/ preservation/research/video-risk/VideoAtRisk_SECTION108_Guidelines_2013.pdf [accessed 8 September 2015].

37. Association of Research Libraries, "Code of Best Practices in Fair Use for Academic and Research Libraries," available online at www.arl.org/storage/documents/publications/code-ofbest-practices-fair-use.pdf [accessed 2 May 2016].

38. Ibid., 17-19.

39. ACRL Guidelines for Media Resources in Academic Libraries Task Force, "Guidelines for Media Resources."

40. Ibid.

41. Harry Kaplanian, Scott Spicer, and Aaron Wood, "How Did That Get in There?: Streaming Media in the Land of Discovery," available online at http://hdl.handle.net/11299/179013 [accessed 20 April 2016].

42. Tara McPherson, "Introduction: Media Studies and the Digital Humanities," Cinema Journal 48, no. 2 (2009): 119-23. 